\title{
PDE5 Exists in Human Neurons and is a Viable Therapeutic Target for Neurologic Disease
}

\author{
Andrew F. Teich ${ }^{\mathrm{a}, \mathrm{b}}$, Mikako Sakurai ${ }^{\mathrm{a}, \mathrm{b}}$, Mitesh Patel $^{\mathrm{a}, \mathrm{b}}$, Cameron Holman $^{\mathrm{a}, \mathrm{b}}$, Faisal Saeed ${ }^{\mathrm{a}, \mathrm{b}}$, \\ Jole Fiorito $^{\mathrm{a}, \mathrm{b}}$ and Ottavio Arancio ${ }^{\mathrm{a}, \mathrm{b}, *}$ \\ ${ }^{a}$ Department of Pathology and Cell Biology, Columbia University, New York, NY, USA \\ ${ }^{\mathrm{b}}$ Taub Institute for Research on Alzheimer's Disease and the Aging Brain, Columbia University, \\ New York, NY, USA
}

Handling Associate Editor: Rada Koldamova

Accepted 24 January 2016

\begin{abstract}
Phosphodiesterase 5 (PDE5) is a critical component of the cGMP-PKG axis of cellular signaling in neurons, and inhibition of PDE5 has been shown to be therapeutic in a wide range of neurologic conditions in animal models. However, enthusiasm for PDE5 inhibitors in humans is limited by data suggesting that PDE5 may not exist in human neurons. Here, we first show that past attempts to quantify PDE5 mRNA were flawed due to the use of incorrect primers, and that when correct primers are used, PDE5 mRNA is detectable in human brain tissue. We then show that PDE5 protein exists in human brain by western blot and ELISA. Most importantly, we performed immunohistochemistry and demonstrate that PDE5 is present in human neurons. We hope that this work will trigger a renewed interest in the development of PDE5 inhibitors for neurologic disease.
\end{abstract}

Keywords: Alzheimer's disease, memory, PDE5 inhibitors, phosphodiesterase 5

\section{INTRODUCTION}

Increasing evidence points to phosphodiesterase 5 (PDE5) as a potential target for treatment in a widerange of neurologic diseases. PDE5 is an enzyme that hydrolyzes cGMP, an important intracellular messenger that activates protein kinase $\mathrm{G}$ (PKG), which then activates a wide-range of intracellular signals [1]. In addition, cGMP activates cyclic nucleotide-gated ion channels, which play an important role in neuronal physiology [2]. Since PDE5 hydrolyzes cGMP, PDE5 is positioned to supply a powerful break to these pathways [3] (and see [4] for a review). This central role of

\footnotetext{
${ }^{*}$ Correspondence to: Ottavio Arancio, Columbia University, New York, NY 10032, USA; P\&S 12-420D, 630W 168th St, New York, NY 10032, USA. Tel.: +1 212342 0533; E-mail: oa1@columbia.edu.
}

PDE5 has led to a large number of animal studies that have validated PDE5 inhibitors as potential therapies for a variety of neurologic diseases. Although many of these studies have focused on Alzheimer's disease, the PDE5 literature suggests that PDE5 inhibition may be therapeutic in a variety of neurological disorders (see Discussion). Despite the successes in the animal literature, PDE5 inhibitors have not been more fully investigated in human studies. This is because there is significant controversy as to whether PDE5 exists in human neurons at all. Although PDE5 is present in rodent brain [5-11] and human fetal brain [12], prior efforts to detect PDE5 in adult human brain tissue have found that PDE5 mRNA levels are either very low [13-15] or undetectable [16]. Those studies that have found low levels of PDE5 mRNA have attributed it to the vasculature [13], and no study has 
looked for PDE5 protein in human brain or attempted to define the cell types in human brain where PDE5 is expressed. These limited human studies have led many to conclude that PDE5 is not a viable therapeutic target for human neurologic disease, and this view has held back development of PDE5 inhibitors in the neurology field. Indeed, a recent study of PDE5 inhibitors in aged rats concluded that PDE5 inhibitors improved spatial memory retention in rats, but also cited the limited evidence of PDE5 in human brain as a major hurdle for the field [17]. Here, we conclusively show that PDE5 exists in human brain tissue, and is expressed in neurons. We hope that this work will trigger a renewed interest in manipulation of the NO-cGMP pathway for neurologic disease.

\section{MATERIALS AND METHODS}

\section{Human tissue}

All human tissue was de-identified and was obtained from the Columbia University Department of Pathology, and as such, is IRB exempt under NIH IRB exemption four (E4). For qPCR, western blot, and ELISA analysis, frozen autopsy tissue was used. For immunohistochemistry, formalin-fixed and paraffin-embedded surgical brain tissue was used. Tissue samples came from adult patients with ages ranging from 18 to 69 , with an average age of 42 . Both male and female tissue was used in our analysis. All quantitative measurements (of mRNA and protein) are averages of three different human samples.

\section{$q P C R$}

Tissue was first homogenized in TRIzol Reagent (Invitrogen), followed by chloroform addition, vortexing, and centrifugation. The aqueous upper layer was pipetted off and added to a new tube, followed by precipitation of RNA/DNA with isopropyl alcohol. The mixture was vortexed, centrifuged, and the supernatant pipetted off, leaving a pellet. The pellet was resuspended in RNase free water, followed by further purification using the RNeasy kit (Qiagen), according to the manufacturer's instructions. Residual DNA was subsequently removed using the DNA free kit from Ambion (AM 1906), and RNA was quantified using a nano-drop spectrophotometer. cDNA was made from RNA using the Invitrogen SuperScript III First-Strand Synthesis System for RT-PCR. Quantitative RT-PCR was performed using SYBR green (Invitrogen) and three different sets of primers. Primer specificity was confirmed with a melting curve. The target of Primer-1, 2 and 3 was the 3'UTR of PDE5 mRNA. Primer-1 forward: 5'-TGATGCAAAGCAGGTG AAACC-3', Reverse: 5'-ATCCAAGGCCATTCCATTTCT-3', Primer-2 forward: 5'-TTCCATGTGCTA GCCAGG TAAA-3', Reverse: 5'-GGTCCAAAACCATGCAC AATTT-3', Primer-3 forward: 5'-ACCGTGCCAAT CACAATCCT'-3', Reverse: 5'-AGCTGCCTTCTG TGACATTCTG-3'. Values were normalized to $\beta$-actin mRNA. $n=3$ for all groups.

\section{Western blotting}

Tissue was homogenized in 3\% LDS buffer (3\% LDS, $10 \mathrm{mM}$ EDTA, $50 \mathrm{mM}$ Tris-HCL) with protease inhibitor (Roche) at $4^{\circ} \mathrm{C}$, followed by centrifugation at $10,000 \mathrm{rpm}$ for $5 \mathrm{~min}$. Supernatant protein was quantified using BCA protein assay reagent (Pierce), and $20 \mathrm{mg}$ of supernatant protein per sample was electrophoresed on NuPAGE 4-12\% Bis-Tris gels (Invitrogen) and then transferred on nitrocellulose membrane using iblot (Invitrogen). The next morning, membranes were blocked for $1 \mathrm{~h}$ in Seablock (Thermo scientific), followed by incubation in primary antibody (Cell signaling (3585) or Atlas (HPA004729)) at 1:1000 for $2 \mathrm{~h}$, washing, and incubation in fluorescently labeled secondary antibody (Thermo scientific \#35571) at 1:10,000 for $1 \mathrm{~h}$. Blot images were taken using Odyssey imaging system (LI-COR). Of note, although the Cell Signaling and Atlas antibodies are from different companies, we are unable to confirm for sure that they react to different epitopes of PDE5, because Cell Signaling does not disclose the region of PDE5 that their antibody reacts to. However, the Atlas antibody works well for both western blot and immunohistochemistry (see below), whereas in our hands the Cell Signaling antibody works well for western blot, but does not work well with our immunohistochemistry protocol. This discrepancy suggests that they are not the same antibody.

\section{ELISA}

Tissue was homogenized in PBS buffer with protease inhibitor (Roche) at $4{ }^{\circ} \mathrm{C}$, followed by centrifugation at $10,000 \mathrm{rpm}$ for $5 \mathrm{~min}$. Supernatant protein was quantified using BCA protein assay reagent (Pierce). Supernatant levels of PDE5 were quantified in cortex, hippocampus, and cerebellum using an ELISA assay (Cusabio Biotech Co., 
LTD; Antibodies-online.com cat. no. ABIN847328). ELISA measurements were performed according to the manufacturer's instructions.

\section{Immunohistochemistry}

Immunohistochemistry was performed with primary antibodies against PDE5 from AbCam (ab64179, which reacts to the C-terminus of PDE5), Santa Cruz (sc-32884, which reacts to the $\mathrm{N}$-terminus of PDE5), and Atlas (HPA004729, which reacts to the central region of PDE5); all slides were counterstained with hematoxylin. Please see manufacturer's website(s) for additional information. Immunostaining was performed in the Ventana automated slide stainer without manual antigen retrieval and was detected using the Ventana ultraView universal DAB detection kit (Tucson, AZ) as recommended by the manufacturer.

\section{RESULTS}

Prior efforts to detect PDE5 in human brain tissue have found that PDE5 mRNA levels are either very low [13-15] or undetectable [16]. However, a careful analysis of the above human studies reveals that some may not have detected PDE5 mRNA for methodologic reasons. For example, in the study that did not find detectable PDE5 transcripts in human brain, a rodent sequence was used to detect human PDE5 mRNA [16]. To answer this question definitively, we used a human sequence and, given that the PDE5 gene has a long 3'UTR (more than $4000 \mathrm{bp}$ long), we chose the 3'UTR. By doing so, we have obtained novel compelling data demonstrating that there is significant PDE5 mRNA in human brain (Fig. 1A). We performed qPCR with three different sets of primers, and we checked transcript levels of mRNA from human cortex. For all three primers we found evidence for PDE5 mRNA. Next, we performed western blot for PDE5 using homogenized human brain tissue. In Fig. 1B, we show a band at $100 \mathrm{kDa}$, the predicted molecular weight of PDE5. We found this band throughout the brain, including in cortex, hippocampus, and cerebellum (Fig. 1B, C) using two different PDE5 antibodies (see Methods). In order to further quantify and validate the western blot results, we performed ELISA for PDE5. The ELISA results for PDE5 are consistent with our western blot data (Fig. 1D), with PDE5 most strongly expressed in cerebellum, and to a lesser degree in cortex and hippocampus.
Taken together, the above data suggest that PDE5 is expressed in the brain. Nevertheless, they do not exclude the possibility that PDE5 is expressed solely in the vasculature. In order to determine whether PDE5 is expressed in neurons, immunohistochemistry for PDE5 was performed on human brain tissue. In Fig. 2, we show that PDE5 is expressed in neurons, and is present in cortex (Fig. 2A1-A3), hippocampus (Fig. 2B1-B3), and cerebellum (Fig. 2C1-C3). In Fig. 2, three different PDE5 antibodies are used, and each antibody reacts against a different epitope within PDE5 (see Methods). Figure 2A1, B1, and C1 use an Abcam antibody, Fig. 2A2, B2, and C2 use a Santa Cruz antibody, and Fig. A3, B3, and C3 use an Atlas antibody.

This study was not designed to provide a comprehensive accounting of all of the cells that are PDE5 positive in human brain. Nevertheless, we did a preliminary analysis of our stained tissue sections to determine the cell types and numbers stained in each region. As noted above, all three antibodies we used stain neurons (see Fig. 2). However, in our hands, the AbCam antibody (seen in Fig. 2A1, B1, and $\mathrm{C} 1$ ) shows the most reliable and robust staining overall, not just in neurons, but also in blood vessels where PDE5 is known to exist [18, 19]. The Atlas antibody is the next best antibody, and the Santa Cruz antibody is the most variable. The subsequent description of our staining refers to the AbCam antibody stained sections, and we recommend this antibody for other groups that are interested in staining human brain tissue for PDE5. The Atlas antibody shows a broadly similar pattern, whereas the Santa Cruz antibody is more variable. In cortex and hippocampus, the neurons that express PDE5 appear to be primarily large, pyramidal-type neurons. In addition to neurons, some glia appear stained, and (as expected) there is staining in the walls of blood vessels. In cortex, the darkest staining is in neurons in relatively superficial layers (i.e., layers 2 and 3). In these superficial layers, approximately $50-70 \%$ of neurons have darker, more robust staining. In hippocampus, most neurons show some staining, although (like cortex) there are subsets of neurons with darker, more robust staining. The proportion of neurons with darker staining appears to vary across the hippocampal formation. Approximately $50 \%$ of dentate gyrus neurons show darker staining. Across the $\mathrm{CA}$ regions, darker staining neurons are more numerous in CA 4, 3, and 2 than in CA 1; approximately $50 \%$ of neurons stain darker in CA 4,3 , and 2, whereas CA1 shows $20-30 \%$ of neurons staining 


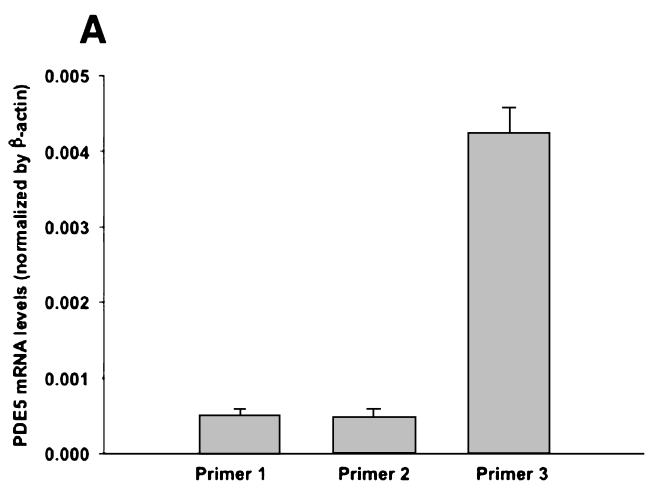

B
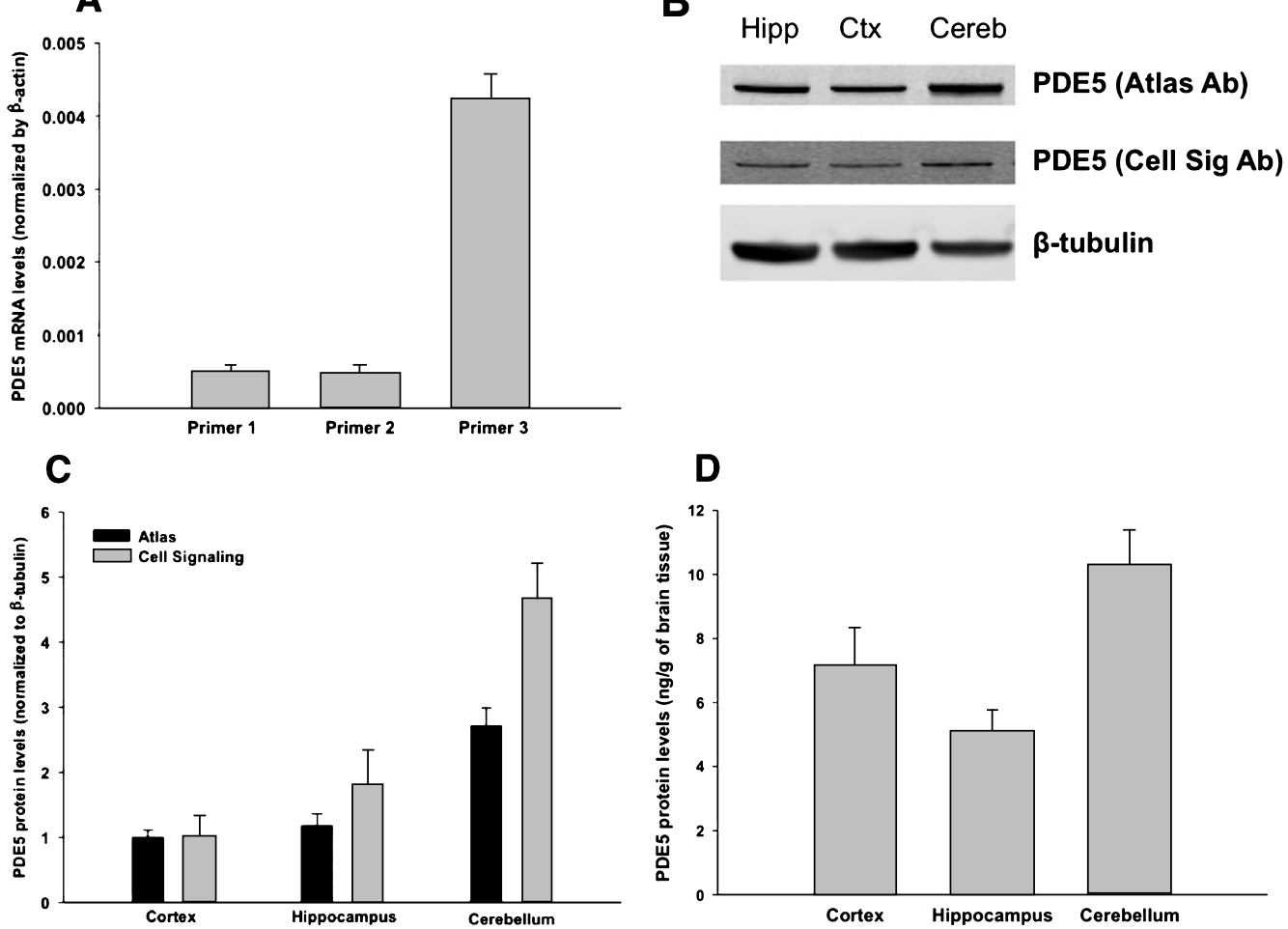

Fig. 1. PDE5 exists in human brain tissue. A) PDE5 mRNA was detected by qPCR in human cortex using 3 different primers (see Methods), against the 3'UTR region (each primer shows the average for 3 samples; error bars are standard error). Values are normalized against $\beta$-actin. B) PDE5 protein was detected in human cortex, hippocampus, and cerebellum by western blot, using two different antibodies to PDE5 (Cell Signaling and Atlas, see methods). All values are normalized by $\beta$-tubulin. Then, for each antibody, the values for hippocampus and cerebellum are normalized to cortex. See Supplementary Information for full, uncut blots. C) Values from B are quantified (3 samples in each group - each sample is from a different human subject; error bars are standard error). We evaluated the results using a two-tailed $t$-test. For both antibodies, there is no statistical difference between cortex and hippocampus ( $p$-value 0.2 for Atlas, 0.09 for Cell Signaling). In contrast, both antibodies show a significant difference between cortex and cerebellum ( $p$-value 0.0006 for Atlas, 0.0014 for Cell Signaling) and between hippocampus and cerebellum ( $p$-value 0.004 for Atlas, 0.014 for Cell Signaling). D) The amount of PDE5 in brain tissue was quantified by ELISA. PDE5 protein was found in the cortex, hippocampus, and cerebellum at a concentration of 7.15, 5.08, and 10.29 $\mathrm{ng} / \mathrm{g}$ of brain tissue, respectively ( 3 samples in each group; error bars are standard error). We evaluated the results using a two-tailed $t$-test. Similarly to the western blot data quantified in panel C, the ELISA data shows no statistical difference between cortex and hippocampus ( $p$-value 0.08), whereas there is a significant difference between cortex and cerebellum ( $p$-value 0.03$)$ as well as between hippocampus and cerebellum ( $p$-value 0.01).

darker. In the cerebellum (Fig. 2C1, C2, and C3), note that Purkinje cells give a robust signal, consistent with the animal literature $[5-9,11]$. In addition, there is also some cerebellar staining in granule layer neurons as well as in the neuropil of the molecular layer.

\section{DISCUSSION}

In this report, we have definitively shown that PDE5 mRNA is detectible in human brain tissue. In addition, we have demonstrated conclusively that PDE5 protein is present in human brain, and is expressed in neurons. These findings should resolve any ambiguity for the relevance of PDE5 as an important drug target for human neurologic disease.

A large number of animal studies have validated PDE5 inhibitors as potential therapies for a variety of neurologic diseases. Many of these studies have demonstrated that PDE5 inhibition rescues memory impairment in a mouse model of Alzheimer's disease [20-23]. However, the therapeutic potential of PDE5 inhibition appears to extend beyond Alzheimer's disease. For example, PDE5 inhibition improves memory in aged rodents [17, 24, 25], and ameliorates memory impairment caused by 


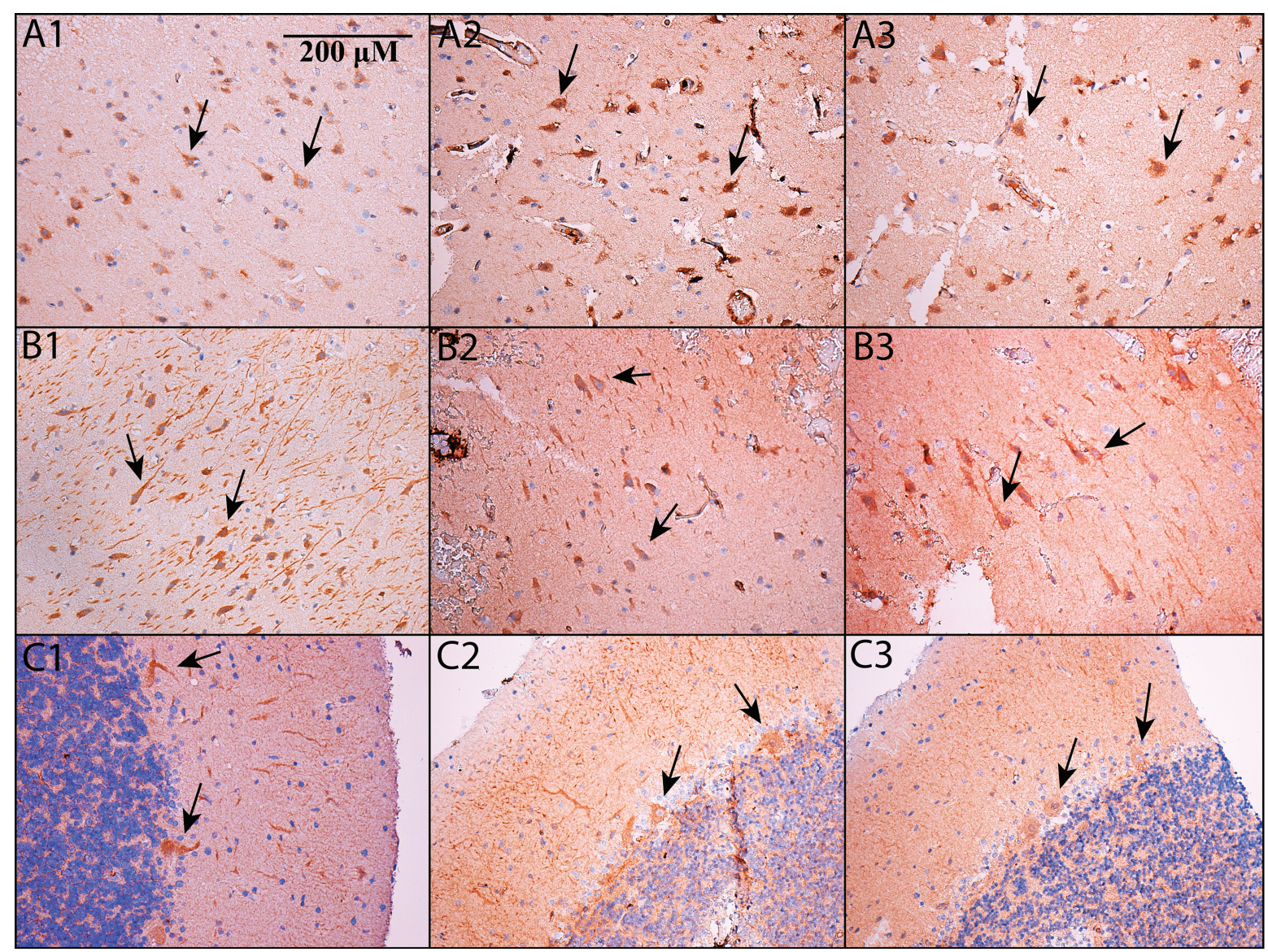

Fig. 2. PDE5 is expressed in neurons. Immunohistochemistry was performed on formalin-fixed, paraffin embedded sections of cortex (A1-A3), hippocampus (B1-B3; shown is subfield CA2/3 - see main text for details) and cerebellum (C1-C3). All images are shown at 200x magnification; the scale bar in Panel A1 applies to all panels. Panels A1, B1, and C1 use an Abcam antibody, panels A2, B2, and C2 use a Santa Cruz antibody, and panels A3, B3, and C3 use an Atlas antibody (see Methods). In all cases, PDE5 is expressed in the cytoplasm of neurons. In cortex and hippocampus, PDE5 is expressed primarily in large, pyramidal-type neurons (see arrows), whereas in cerebellum, it is prominent in Purkinje neurons (see arrows).

pharmacologic agents [26-29]. PDE5 inhibition also rescues memory impairment in diabetic conditions and electroconvulsive shock-induced animal models [30]. Memory enhancement by PDE5 inhibitors is also found not only in rodents, but also in chicks [31] and monkeys [32]. Finally, the neurologic benefits of PDE5 inhibition extend beyond memory enhancement. PDE5 inhibition also enhances the effect of anti-epileptic drugs [33], and may also be therapeutic in the setting of ischemic damage [34] and focal brain injury [35]. Thus, PDE5 stands out as a unique target in the brain that may be therapeutically exploited in a variety of neurologic conditions.

Although there is widespread skepticism as to whether PDE5 exists in human neurons [13-16], there have been a small number of studies of PDE5 inhibition and cognition. Although the literature is limited, there is evidence that chronic PDE5 inhibition may be neurologically beneficial. For example, although a single dose of sildenafil does not cause a clear improvement in cognition in healthy adults [36], chronic administration of udenafil has been shown to lead to an improvement in both general cognitive function as well as frontal executive function [37]. This has led some to suggest that in humans, the therapeutic benefits of PDE5 inhibition may be best seen after chronic inhibition rather than after a single dose [38]. We hope that the results presented in this report will motivate further investigation of these limited (but promising) findings. 
In humans, PDE5 inhibitors (such as sildenafil) are already widely used for non-neurologic conditions, and the side-effect profile of these drugs is well known and well tolerated by the majority of users. For example, one study of 532 men taking a 24-week course of sildenafil showed that the most serious side effects reported were headaches, flushing, dyspepsia, rhinitis, and visual disturbances. However, these side effects were reported in a minority of users, and $92 \%$ of men in a separate trial completed a 32-week extension study [39, 40]. Tadalafil (another PDE5 inhibitor) was studied in seven double-blind, placebocontrolled trials (involving over 4000 subjects) before approval [40-43]. These trials confirmed the benign side-effect profile of PDE5 inhibition, with one trial noting only $6.3 \%$ of subjects discontinuing medication due to adverse events [41]. Currently available PDE5 inhibitors may not be optimized for CNS delivery, and thus, more work needs to be done before PDE5 inhibitors are an option for neurologic disease. However, the extensive data to date suggest that this class of drugs would be a safe and well-tolerated therapy.

In summary, we believe that the work presented here is uniquely important from a medical perspective. First of all, this work validates the relevance of a large body of animal research on PDE5 for human neurologic disease. Second of all, PDE5 inhibitors are widely used for other non-neurologic conditions, and so the side-effect profile of this class of drugs is mild and well characterized. Thus, we believe that PDE5 inhibitors have therapeutic potential for a variety of neurologic diseases, and we hope the work presented here stimulates future research in this field.

\section{ACKNOWLEDGMENTS}

This work was supported by NIH grants U01-AG032973 (OA) and UL1-TR000040 (AFT), Alzheimer's Association grant NIRG-13-283742 (AFT), and a grant from the Louis V. Gerstner, Jr. Scholars Program (AFT).

Authors' disclosures available online (http://j-alz. com/manuscript-disclosures/15-1104r1).

\section{SUPPLEMENTARY MATERIAL}

The supplementary material is available in the electronic version of this article: http://dx.doi.org/ 10.3233/JAD-151104.

\section{REFERENCES}

[1] Wang X, Robinson PJ (1997) Cyclic GMP-dependent protein kinase and cellular signaling in the nervous system. J Neurochem 68, 443-456.

[2] Wei JY, Jin X, Cohen ED, Daw NW, Barnstable CJ (2002) cGMP-induced presynaptic depression and postsynaptic facilitation at glutamatergic synapses in visual cortex. Brain Res 927, 42-54.

[3] Marte A, Pepicelli O, Cavallero A, Raiteri M, Fedele E (2008) In vivo effects of phosphodiesterase inhibition on basal cyclic guanosine monophosphate levels in the prefrontal cortex, hippocampus and cerebellum of freely moving rats. J Neurosci Res 86, 3338-3347.

[4] Bender AT, Beavo JA (2006) Cyclic nucleotide phosphodiesterases: Molecular regulation to clinical use. Pharmacol Rev 58, 488-520.

[5] Van Staveren WC, Steinbusch HW, Markerink-Van Ittersum M, Repaske DR, Goy MF, Kotera J, Omori K, Beavo JA, De Vente J (2003) mRNA expression patterns of the cGMP-hydrolyzing phosphodiesterases types 2,5 , and 9 during development of the rat brain. J Comp Neurol 467, 566-580.

[6] Kotera J, Fujishige K, Omori K (2000) Immunohistochemical localization of cGMP-binding cGMP-specific phosphodiesterase (PDE5) in rat tissues. J Histochem Cytochem 48, 685-693.

[7] Kotera J, Yanaka N, Fujishige K, Imai Y, Akatsuka H, Ishizuka T, Kawashima K, Omori K (1997) Expression of rat cGMP-binding cGMP-specific phosphodiesterase mRNA in Purkinje cell layers during postnatal neuronal development. Eur J Biochem 249, 434-442.

[8] Bender AT, Beavo JA (2004) Specific localized expression of cGMP PDEs in Purkinje neurons and macrophages. $\mathrm{Neu}$ rochem Int 45, 853-857.

[9] Giordano D, De Stefano ME, Citro G, Modica A, Giorgi M (2001) Expression of cGMP-binding cGMP-specific phosphodiesterase (PDE5) in mouse tissues and cell lines using an antibody against the enzyme amino-terminal domain. Biochim Biophys Acta 1539, 16-27.

[10] van Staveren WC, Steinbusch HW, Markerink-van Ittersum M, Behrends S, de Vente J (2004) Species differences in the localization of cGMP-producing and NO-responsive elements in the mouse and rat hippocampus using cGMP immunocytochemistry. Eur J Neurosci 19, 21552168.

[11] Shimizu-Albergine M, Rybalkin SD, Rybalkina IG, Feil R, Wolfsgruber W, Hofmann F, Beavo JA (2003) Individual cerebellar Purkinje cells express different cGMP phosphodiesterases (PDEs): In vivo phosphorylation of cGMP-specific PDE (PDE5) as an indicator of cGMPdependent protein kinase (PKG) activation. $J$ Neurosci $\mathbf{2 3}$, 6452-6459.

[12] BrainSpan, BrainSpan Atlas of the Developing Human Brain, Brainspan Consortium Members, http://www. brainspan.org/static/home.

[13] Lakics V, Karran EH, Boess FG (2010) Quantitative comparison of phosphodiesterase mRNA distribution in human brain and peripheral tissues. Neuropharmacology 59, 367374.

[14] Loughney K, Hill TR, Florio VA, Uher L, Rosman GJ, Wolda SL, Jones BA, Howard ML, McAllister-Lucas LM, Sonnenburg WK, Francis SH, Corbin JD, Beavo JA, Ferguson K (1998) Isolation and characterization of cDNAs 
encoding PDE5A, a human cGMP-binding, cGMP-specific 3', 5'-cyclic nucleotide phosphodiesterase. Gene 216, 139147.

[15] Yanaka N, Kotera J, Ohtsuka A, Akatsuka H, Imai Y, Michibata H, Fujishige K, Kawai E, Takebayashi S, Okumura K, Omori K (1998) Expression, structure and chromosomal localization of the human cGMP-binding cGMP-specific phosphodiesterase PDE5A gene. Eur J Biochem 255, 391399.

[16] Reyes-Irisarri E, Markerink-Van Ittersum M, Mengod G, de Vente J (2007) Expression of the cGMP-specific phosphodiesterases 2 and 9 in normal and Alzheimer's disease human brains. Eur J Neurosci 25, 3332-3338.

[17] Devan BD, Pistell PJ, Duffy KB, Kelley-Bell B, Spangler EL, Ingram DK (2014) Phosphodiesterase inhibition facilitates cognitive restoration in rodent models of age-related memory decline. NeuroRehabilitation 34, 101-111.

[18] Stegbauer J, Friedrich S, Potthoff SA, Broekmans K, Cortese-Krott MM, Quack I, Rump LC, Koesling D, Mergia E (2013) Phosphodiesterase 5 attenuates the vasodilatory response in renovascular hypertension. PLoS One $\mathbf{8}$, e80674.

[19] Roustit M, Hellmann M, Cracowski C, Blaise S, Cracowski JL (2012) Sildenafil increases digital skin blood flow during all phases of local cooling in primary Raynaud's phenomenon. Clin Pharmacol Ther 91, 813-819.

[20] Puzzo D, Staniszewski A, Deng SX, Privitera L, Leznik E, Liu S, Zhang H, Feng Y, Palmeri A, Landry DW, Arancio O (2009) Phosphodiesterase 5 inhibition improves synaptic function, memory, and amyloid-beta load in an Alzheimer's disease mouse model. J Neurosci 29, 80758086.

[21] Jin F, Gong QH, Xu YS, Wang LN, Jin H, Li F, Li LS, Ma YM, Shi JS (2014) Icariin, a phosphodiesterase-5 inhibitor, improves learning and memory in APP/PS1 transgenic mice by stimulation of NO/cGMP signalling. Int $J$ Neuropsychopharmacol 17, 871-881.

[22] Zhang J, Guo J, Zhao X, Chen Z, Wang G, Liu A, Wang Q, Zhou W, Xu Y, Wang C (2013) Phosphodiesterase-5 inhibitor sildenafil prevents neuroinflammation, lowers beta-amyloid levels and improves cognitive performance in APP/PS1 transgenic mice. Behav Brain Res 250, 230-237.

[23] Cuadrado-Tejedor M, Hervias I, Ricobaraza A, Puerta E, Perez-Roldan JM, Garcia-Barroso C, Franco R, Aguirre N, Garcia-Osta A (2011) Sildenafil restores cognitive function without affecting beta-amyloid burden in a mouse model of Alzheimer's disease. Br J Pharmacol 164, 2029-2041.

[24] Baratti CM, Boccia MM (1999) Effects of sildenafil on longterm retention of an inhibitory avoidance response in mice. Behav Pharmacol 10, 731-737.

[25] Prickaerts J, de Vente J, Honig W, Steinbusch HW, Blokland A (2002) cGMP, but not cAMP, in rat hippocampus is involved in early stages of object memory consolidation. Eur J Pharmacol 436, 83-87.

[26] Erceg S, Monfort P, Hernandez-Viadel M, Rodrigo R, Montoliu C, Felipo V (2005) Oral administration of sildenafil restores learning ability in rats with hyperammonemia and with portacaval shunts. Hepatology 41, 299306.

[27] Devan BD, Pistell PJ, Daffin LW Jr, Nelson CM, Duffy KB, Bowker JL, Bharati IS, Sierra-Mercado D, Spangler EL,
Ingram DK (2007) Sildenafil citrate attenuates a complex maze impairment induced by intracerebroventricular infusion of the NOS inhibitor Nomega-nitro-L-arginine methyl ester. Eur J Pharmacol 563, 134-140.

[28] Devan BD, Bowker JL, Duffy KB, Bharati IS, Jimenez M, Sierra-Mercado D Jr, Nelson CM, Spangler EL, Ingram DK (2006) Phosphodiesterase inhibition by sildenafil citrate attenuates a maze learning impairment in rats induced by nitric oxide synthase inhibition. Psychopharmacology (Berl) 183, 439-445.

[29] Devan BD, Sierra-Mercado D Jr, Jimenez M, Bowker JL, Duffy KB, Spangler EL, Ingram DK (2004) Phosphodiesterase inhibition by sildenafil citrate attenuates the learning impairment induced by blockade of cholinergic muscarinic receptors in rats. Pharmacol Biochem Behav 79, 691-699.

[30] Patil CS, Singh VP, Kulkarni SK (2006) Modulatory effect of sildenafil in diabetes and electroconvulsive shockinduced cognitive dysfunction in rats. Pharmacol Rep $\mathbf{5 8}$, 373-380.

[31] Campbell E, Edwards T (2006) Zaprinast consolidates longterm memory when administered to neonate chicks trained using a weakly reinforced single trial passive avoidance task. Behav Brain Res 169, 181-185.

[32] Rutten K, Basile JL, Prickaerts J, Blokland A, Vivian JA (2008) Selective PDE inhibitors rolipram and sildenafil improve object retrieval performance in adult cynomolgus macaques. Psychopharmacology (Berl) 196, 643648.

[33] Nieoczym D, Socala K, Jedziniak P, Olejnik M, Wlaz P (2013) Effect of sildenafil, a selective phosphodiesterase 5 inhibitor, on the anticonvulsant action of some antiepileptic drugs in the mouse $6-\mathrm{Hz}$ psychomotor seizure model. Prog Neuropsychopharmacol Biol Psychiatry 47, 104-110.

[34] Barros-Minones L, Martin-de-Saavedra D, Perez-Alvarez S, Orejana L, Suquia V, Goni-Allo B, Hervias I, Lopez MG, Jordan J, Aguirre N, Puerta E (2013) Inhibition of calpainregulated $\mathrm{p} 35 / \mathrm{cdk} 5$ plays a central role in sildenafil-induced protection against chemical hypoxia produced by malonate. Biochim Biophys Acta 1832, 705-717.

[35] Prado J, Pifarre P, Giralt M, Hidalgo J, Garcia A (2013) Metallothioneins I/II are involved in the neuroprotective effect of sildenafil in focal brain injury. Neurochem Int 62 , 70-78.

[36] Grass H, Klotz T, Fathian-Sabet B, Berghaus G, Engelmann U, Kaferstein H (2001) Sildenafil (Viagra): Is there an influence on psychological performance? Int Urol Nephrol 32, 409-412.

[37] Shim YS, Pae CU, Kim SW, Kim HW, Kim JC, Koh JS (2011) Effects of repeated dosing with Udenafil (Zydena) on cognition, somatization and erection in patients with erectile dysfunction: A pilot study. Int J Impot Res $\mathbf{2 3}$, 109-114.

[38] Reneerkens OA, Sambeth A, Ramaekers JG, Steinbusch HW, Blokland A, Prickaerts J (2013) The effects of the phosphodiesterase type 5 inhibitor vardenafil on cognitive performance in healthy adults: A behavioralelectroencephalography study. J Psychopharmacol 27, 600-608.

[39] Goldstein I, Lue TF, Padma-Nathan H, Rosen RC, Steers WD, Wicker PA (1998) Oral sildenafil in the treatment of erectile dysfunction. Sildenafil Study Group. N Engl J Med 338, 1397-1404. 
[40] Smith WB, 2nd, McCaslin IR, Gokce A, Mandava SH, Trost L, Hellstrom WJ (2013) PDE5 inhibitors: Considerations for preference and long-term adherence. Int J Clin Pract 67, 768-780.

[41] Montorsi F, Verheyden B, Meuleman E, Junemann KP, Moncada I, Valiquette L, Casabe A, Pacheco C, Denne J, Knight J, Segal S, Watkins VS (2004) Long-term safety and tolerability of tadalafil in the treatment of erectile dysfunction. Eur Urol 45, 339-344; discussion 344-335.
[42] Seftel AD, Wilson SK, Knapp PM, Shin J, Wang WC, Ahuja S (2004) The efficacy and safety of tadalafil in United States and Puerto Rican men with erectile dysfunction. J Urol 172, 652-657.

[43] Brock GB, McMahon CG, Chen KK, Costigan T, Shen W, Watkins V, Anglin G, Whitaker S (2002) Efficacy and safety of tadalafil for the treatment of erectile dysfunction: Results of integrated analyses. J Urol 168, 1332-1336. 